\title{
Multi-decadal changes in structural complexity following mass coral mortality on a Caribbean reef
}

\author{
George Roff $^{1}$, Jennifer Joseph ${ }^{2}$, and Peter J. Mumby ${ }^{1}$ \\ ${ }^{1}$ Marine Spatial Ecology Lab, School of Biological Sciences, University of Queensland, QLD 4072, Australia \\ ${ }^{2}$ College of Earth, Ocean and Environment, University of Delaware, Newark, DE, USA
}

Correspondence: George Roff (g.roff@uq.edu.au)

Received: 23 August 2019 - Discussion started: 26 September 2019

Revised: 12 June 2020 - Accepted: 24 June 2020 - Published: 1 December 2020

\begin{abstract}
In recent decades, extensive mortality of reefbuilding corals throughout the Caribbean region has led to the erosion of reef frameworks and declines in biodiversity. Using field observations, structural models, and highprecision U-Th dating methods, we quantify changes in structural complexity in the major framework-building coral Orbicella annularis over a 20-year period at Long Caye (Belize). Despite extensive mortality following the mass coral bleaching event of 1998, the structural complexity of frameworks remained largely unchanged between 1998 (rugosity index, $R$, of $2.35 \pm 0.1$ ) and 2018 ( $R$ of $2.29 \pm 0.1$ ). Colony-scale structural complexity was maintained, as the rapid growth of surviving ramets $\left(0.69 \pm 0.1 \mathrm{~cm} \mathrm{yr}^{-1}\right)$ offset the slower bioerosion of dead ramets $\left(-0.11 \pm 0.16 \mathrm{~cm} \mathrm{yr}^{-1}\right)$. Despite the apparent stability of the structural complexity at colony scales, bioerosion of individual dead ramets over 2 decades led to declines in microhabitat complexity, with an overall reduction in the depth of microhabitats within frameworks. Altered microhabitat complexity appears to have negative effects on cryptic fauna, with the grazing urchin Echinometra viridis declining from $1.5 \pm 0.4$ individuals $\mathrm{m}^{-2}$ in 1998 to $0.02 \pm$ individuals $\mathrm{m}^{-2}$ in 2018 . Changes in microhabitat complexity have the potential to alter ecological interactions that can impact recovery dynamics on coral reefs in ways that are undetectable using traditional rugosity metrics of structural complexity.
\end{abstract}

\section{Introduction}

As an ecosystem engineer, Orbicella annularis (Ellis and Solander, 1786) plays a critical ecosystem role as a framework-building coral in the Caribbean (Geister, 1977) providing reef-scale structural complexity that supports a diverse range of fish (Alvarez-Filip et al., 2011) and invertebrate (Idjadi and Edmunds, 2006) assemblages. From a geological perspective, $O$. annularis first appeared in the late Pliocene to early Pleistocene ( 2-1.5 Myr ago, Budd and Klaus, 2001) and linear extension of $\sim 10 \mathrm{~mm} \mathrm{yr}^{-1}$ resulted in the accretion of modern day Caribbean coral reefs at a rate of $\sim 3.3 \mathrm{~m} \mathrm{kyr}^{-1}$ (Gischler, 2008). Accretion of reef frameworks is a key ecosystem function, providing critical habitat for reef organisms and physical coastline protection from wave erosion (Moberg and Folke, 1999).

While Caribbean coral reefs have exhibited remarkable ecological persistence over geological time frames (Pandolfi and Jackson, 2006), reefs throughout the region have declined over the past century due to climate change, overfishing and poor water quality (Knowlton and Jackson, 2008). In recent decades, populations of $O$. annularis have been decimated by recurrent coral bleaching events (Szmant and Gassman, 1990), disease outbreaks (Pantos et al., 2003; Bruno et al., 2003), and increasing negative interactions with macroalgae (Ferrari et al., 2012) resulting in region-wide declines of $O$. annularis and shifts in population structure to higher densities of smaller colonies (Nugues, 2002; Bruckner and Bruckner, 2006; Edmunds, 2015). Following the loss of living coral tissue, the exposed coral skeleton is subjected to a gradual process of bioerosion - the biologically induced weakening and breaking down of coral skeletons (Glynn and Manzello, 2015). 
On modern-day coral reefs, grazing parrotfish are the primary bioeroders, contributing to between $79 \%$ and $84 \%$ of the total bioerosion (Perry et al., 2014). Parrotfish scrape and excavate the external surfaces of coral reef frameworks (Clements et al., 2017), producing large volumes of carbonate sediments. Colonization of exposed framework substrates by a broad range of micro- and macro-boring organisms, including sponges, endolithic algae, fungi, and boring invertebrates further weakens coral skeletons, making them more susceptible to physical erosion (Hutchings, 1986). The erosion of reef frameworks in the Caribbean over the past few decades has resulted in a loss of reef-scale structural complexity, a process described as "flattening" (Alvarez-Filip et al., 2009). This region-wide loss of structural complexity has led to substantial declines in ecosystem functioning, including reductions in biodiversity (Newman et al., 2015) and decreases in fisheries' productivity (Rogers et al., 2018).

As the processes of accretion and erosion of coral reef frameworks occur over decadal to centennial time frames (Glynn and Manzello, 2015), few long-term in situ studies of bioerosion exist (but see Kuffner et al., 2019). Here, we return to a multi-decadal study of Caribbean coral frameworks in Glovers Reef, Belize (Roff et al., 2015; Mumby, 1999). In 1998, extreme thermal stress and the impact of Hurricane Mitch resulted in extensive coral mortality throughout the Mesoamerican Barrier Reef (Mumby, 1999; Aronson et al., 2002; Mumby et al., 2005). Projections of future thermal stress events indicate that such mass bleaching events may become an annual occurrence by 2040 (van Hooidonk et al., 2015). These events are predicted to have a strong negative impact on carbonate budgets and reef accretion (Kennedy et al., 2013; Perry et al., 2013), yet the landscape-scale impacts on the structure and function of coral frameworks are not well understood. Here we quantify multi-decadal changes in O. annularis frameworks at Long Caye (Glovers Reef) and quantify long-term changes in structural complexity and microhabitat complexity.

\section{Results and discussion}

Prior to the 1998 mass bleaching event, frameworks at Long Caye (Glovers Reef, Fig. 1a) were dominated by large longlived $O$. annularis colonies (Fig. 1b). Surveys at Long Caye in June 1998 (10 m depth) revealed high levels of healthy $O$. annularis cover $(68 \pm 14 \%)$. Major coral bleaching occurred in September 1998 following a period of calm weather and elevated water temperatures, with $70 \%$ to $90 \%$ of $O$. annularis colonies exhibiting full or partial bleaching (Roff et al., 2015). Extensive wave damage from Hurricane Mitch in November 1998 compounded the impacts of bleaching, with $\sim 85 \%$ of $O$. annularis colonies exhibiting partial mortality (Roff et al., 2015). By June 2000, cover of $O$. annularis had declined to $20 \pm 5 \%$, and it remained at $\sim 15 \%$ in the decades following the mass bleaching event despite repeated minor hurricane disturbances (Fig. 1c). Genetic analysis of the surviving $O$. annularis colonies at Long Caye indicates high levels of genotypic diversity compared with other reefs around the Caribbean (Foster et al., 2013). Field surveys in 2018 revealed high levels of macroalgal cover and extensive partial mortality within $O$. annularis colonies (Fig. 2a), with low survival of $O$. annularis ramets within colonies (averaging $14.1 \pm 11 \%$ ).

To determine changes in $O$. annularis frameworks at different scales, we calculated two metrics of habitat complexity: (i) microhabitat complexity at the scale of individual ramets (centimetres) and (ii) structural complexity at the scale of whole colonies (metres). These metrics consider the upper surfaces of $O$. annularis colonies, and they differ from traditional transect-chain measurements of reef rugosity that assess structural complexity across multiple colonies (e.g. Alvarez-Filip et al., 2011). Microhabitat complexity of $O$. annularis provides critical permanent refugia for small reef fish and cryptic invertebrates among ramets (Almany, 2004; Sammarco, 1982), and structural complexity at colony scales can reduce the foraging efficiency of predators and limit prey detection (Beukers and Jones, 1998).

\subsection{Multi-decadal changes in microhabitat complexity}

Prior to the 1998 mortality event, ramet heights within colonies were consistent, resulting in an even hemispherical colony appearance (Fig. 1b). Surveys in 2018 revealed that surviving colonies exhibited a characteristic "serrated" topography: the isolated surviving ramets protruded above the remaining dead colony (Figs. 2a and S1 in the Supplement). As grazing parrotfish exhibit a strong tendency to erode the surfaces rather than sides of ramets (Roff et al., 2015), we focused on vertical erosion on the upper surfaces of dead ramets. We hypothesized that the differences in growth among surviving ramets and the erosion of dead ramets would result in changes in microhabitat complexity. To test this hypothesis, we measured height differences between live and dead ramet pairings from $O$. annularis colonies at Long Caye in successive decades, 2007 and 2018 (Fig. 2b). Measurements of ramet pairings in 2007 indicated a significant difference in height between "live" and "dead" ramets of $3.1 \pm 2.9 \mathrm{~cm}(p<0.01$, Fig. $2 \mathrm{c})$, which is a trend that increased to $15.5 \pm 3.8 \mathrm{~cm}$ in 2018 ( $p<0.01$, Fig. $2 \mathrm{c})$. No significant difference in height $(p>0.05)$ was observed between "live-live" or "dead-dead" ramet pairings in either $2007(0.5 \pm 1.0,1.2 \pm 0.9 \mathrm{~cm})$ or $2018(0.1 \pm 1.2,0.6 \pm 1.4 \mathrm{~cm})$, implying that the processes of growth and/or erosion occur evenly among living and dead ramets (Fig. S1).

Using high-precision U-Th dating methods and CT scan reconstructions, we previously quantified annual rates of external bioerosion and growth (linear extension) of $O$. annularis colonies at Long Caye between 1998 and 2011 (Roff et al., 2015). Estimates from U-Th dates indicated an average erosion rate of $-0.11 \pm 0.16 \mathrm{~cm} \mathrm{yr}^{-1}$, which was in close 


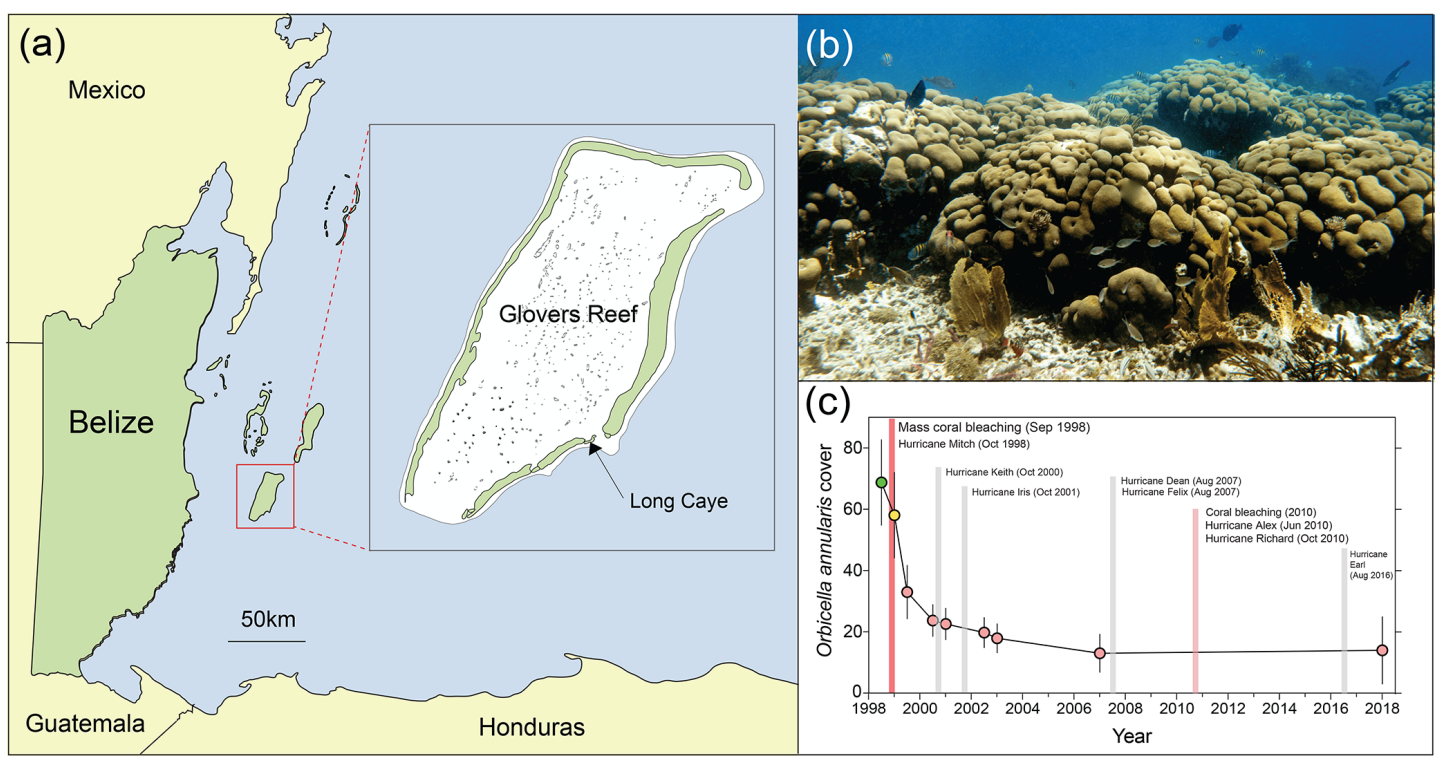

Figure 1. (a) Map of Belize and the study site (inset) at Long Caye, Glovers Reef. (b) Living Orbicella annularis colonies forming a structurally complex framework on a Caribbean reef. (c) Time series of $O$. annularis cover at Glovers Reef and major disturbance events between 1998 and 2018.

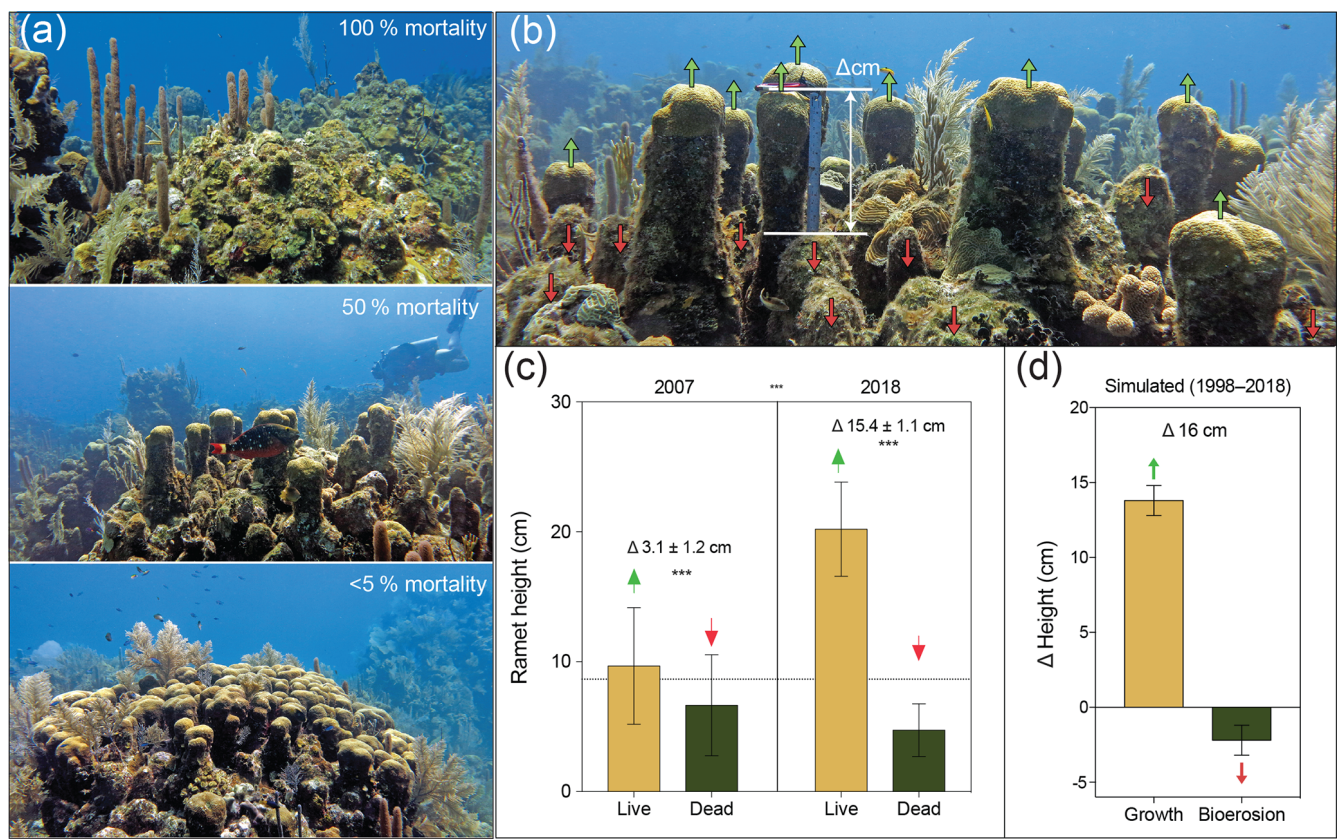

Figure 2. (a) Orbicella annularis colonies from Long Caye in 2018, indicating high survival following the mass bleaching event $(<5 \%$ mortality), complete $(100 \%)$ mortality followed by algal overgrowth by Lobophora variegata, and partial mortality $(\sim 50 \%)$ resulting in a characteristic "serrated" pattern and gaps. (b) The O. annularis framework at Long Caye in 2007, showing the growth of surviving ramets (green arrows) protruding above the eroding dead ramets (red arrows) and the difference in height between live and dead ramets (scale ruler is equal to $15 \mathrm{~cm}$ ). (c) The height of "live" and "dead" ramet pairings in 2007 and 2018, showing a significant difference in height within years and a significant difference in the average height of live ramets within years (*** denotes $p<0.001$ ). (d) Simulated growth and bioerosion between 1998 and 2018 based upon a linear erosion rate of $0.11 \pm 0.03 \mathrm{~cm} \mathrm{yr}^{-1}$ and a growth rate of $0.69 \pm 0.1 \mathrm{~cm} \mathrm{yr}^{-1}$ (Roff et al., 2015 ). 
agreement with model predictions of external erosion by excavating parrotfish (Roff et al., 2015). Within the same time frame, linear extension (growth) of $O$. annularis ramets (as quantified by density banding of skeletons) was more than sixfold higher $\left(0.69 \pm 0.1 \mathrm{~cm} \mathrm{yr}^{-1}\right)$ than surface bioerosion (Roff et al., 2015). Based upon these parameters, an estimate of the ramet height difference between 1998 and 2018 would indicate a $\sim 13.8 \pm 2 \mathrm{~cm}$ vertical growth of surviving $O$. annularis ramets, whereas bioerosion drove a $\sim-2.2 \pm 1 \mathrm{~cm}$ loss of ramet height. The modelled net outcome of the erosion and growth of ramets of $\Delta 16 \mathrm{~cm}$ between 1998 and 2018 (Fig. 2d) is in close agreement with the observed differences of $15.4 \pm 1.1 \mathrm{~cm}$ between live and dead ramets in 2018, indicating that the sixfold higher growth of surviving ramets results in the observed "serrated" pattern seen in $O$. annularis colonies (Fig. 2b).

\subsection{Multi-decadal changes in structural complexity}

To determine changes in structural complexity at colony scales, we created a structural model of $O$. annularis colonies (Fig. 3a) that was parameterized using field data collected at Long Caye (see Sect. 4 for complete details and model code). Briefly, the model simulates annual changes in structural complexity of 1000 O. annularis colonies between 1998 and 2018 through the growth of surviving ramets and the erosion of dead ramets (Fig. 3a). Structural complexity within each simulated colony was measured using the rugosity index $(R$, Fig. 3), which is a common index of rugosity on coral reefs: a flat surface has an $R$ of 1 and larger numbers reflect a greater degree of structural complexity (AlvarezFilip et al., 2009). Prior to the bleaching event in 1998, uniform growth of living $O$. annularis ramets resulted in $R$ values of 2.36 (95\% confidence interval, CI, of 2.3-2.4). Following the bleaching event, extensive partial mortality resulted in the erosion of dead ramets and the growth of surviving ramets. Hindcasting long-term changes in structural complexity between 1998 and 2018 revealed high variability among colony trajectories, with $58 \%$ exhibiting declining rugosity, $41 \%$ exhibiting increases in rugosity, and $1 \%$ exhibiting no change. Despite such variance, overall structural complexity was remarkably stable (Fig. 3b), and average values of $R$ in 2018 were within the range of premortality levels ( $R$ of $2.31,95 \%$ CI of $2.28-2.34$ ). Sensitivity analysis of the model indicates that changes in structural complexity between 1998 and $2018(\Delta R)$ was weakly correlated to colony size ( $\rho$ of $0.1,95 \%$ CI of $0.04-0.15$ ): smaller colonies experienced declines in structural complexity (Fig. 3c). Post-disturbance survival was a key driver of change in rugosity ( $\rho$ of $0.79,95 \%$ CI of $0.75-0.8$ ) in that colonies that experienced high levels of within colony mortality (> 80\%) also experienced declines in structural complexity (Fig. 3d), whereas colonies that experienced higher survival rates ( $>20 \%$ surviving ramets within colonies) exhibited increases in structural complexity (Fig. 3d). Com- parisons of structural complexity reconstructed from paired photographs of $O$. annularis colonies at Long Caye in 2003 and 2018 (Fig. 4a, b) validate model predictions and support wider field observations at Glovers Reef in 2018 of surviving ramets protruding above dead $O$. annularis frameworks (Fig. S1).

Losses of structural complexity following disturbance are primarily thought to be driven by processes of erosion (Alvarez-Filip et al., 2009; Sheppard et al., 2002; Glynn, 1988): physical disturbance and chemical dissolution combined with intense internal and external bioerosion flatten structurally complex coral reef frameworks. If processes of bioconstruction from coral growth are weak, reefs remain in a degraded and flattened state, as has occurred in several areas of the Caribbean to varying extents (Alvarez-Filip et al., 2009). Here, we document changes in microhabitat complexity following mass coral mortality that appear to be driven primarily by the growth of surviving ramets of $O$. annularis rather than by processes of bioerosion. High levels of genotypic diversity in $O$. annularis at Long Caye (Foster et al., 2013) and population connectivity to other reefs throughout the western Caribbean (Foster et al., 2012) imply that Long Caye is not unique, and differential growth of surviving ramets may lead to similar changes in structural complexity for $O$. annularis-dominated frameworks elsewhere in the Caribbean (e.g. Idjadi and Edmunds, 2006; Edmunds and Elahi, 2007) when growth rates exceed erosion. At colony scales, changes in microhabitat complexity do not appear to have translated into changes in reef complexity, as the erosion of dead ramets is offset by the growth of surviving ramets. This apparent stability in reef complexity at Long Caye is intrinsically linked to the columnar growth form of $O$. annularis colonies (Fig. 2), and trajectories of erosion and structural complexity will likely vary among other Caribbean coral species with different morphologies (e.g. O. faveolata). In colonies of $O$. annularis that experienced partial mortality, the wide spacing among surviving ramets (Fig. 2c) allows grazing parrotfish to access previously protected skeleton (see initial phase Sparisoma viride, Fig. 1c). This increased access to parrotfish appears to have accelerated erosion rates on the sides of surviving ramets, resulting in a narrowing of ramets (Fig. S1) which increases susceptibility to physical breakage (Hein and Risk, 1975).

Long-term records of bioerosion over ecologically meaningful timescales are rare; however, a recent study (Kuffner et al., 2019) reporting exceptionally rapid rates of erosion of dead $O$. faveolata reef frameworks (maximum $1.63 \mathrm{~cm} \mathrm{yr}^{-1}$ ) in the Florida Keys provides important insight into the heterogeneity of framework erosion throughout the wider Caribbean. The low rates of $O$. annularis bioerosion at Long Caye reported in the present study $(-2.2 \pm 1 \mathrm{~cm}$ over 20 years) compared with the Florida Keys $(9.4 \pm 5.6 \mathrm{~cm}$ over 17 years) is likely due to differences in skeletal density, $1.9 \mathrm{~g} \mathrm{~cm}^{3}$ (Roff et al., 2015) vs. $1.12 \mathrm{~g} \mathrm{~cm}^{3}$ (Halley et al., 1994), driven by the highly productive windward location of 
(a)

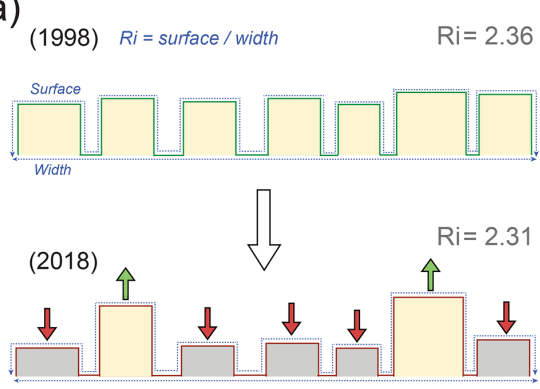

(c)

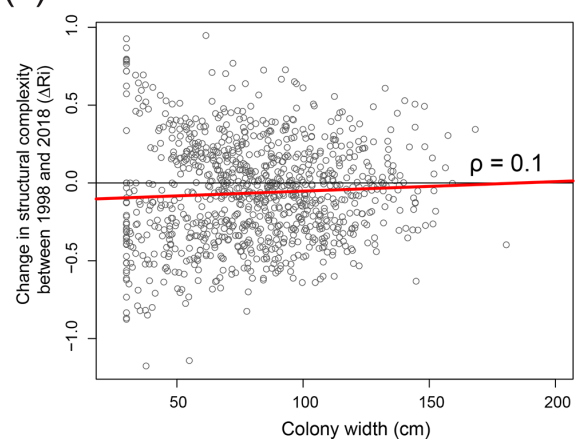

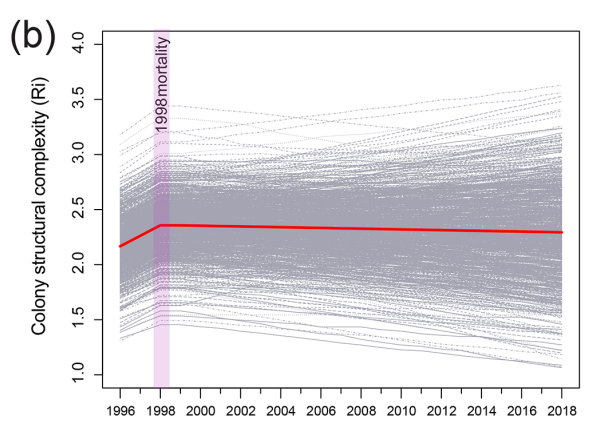

Year

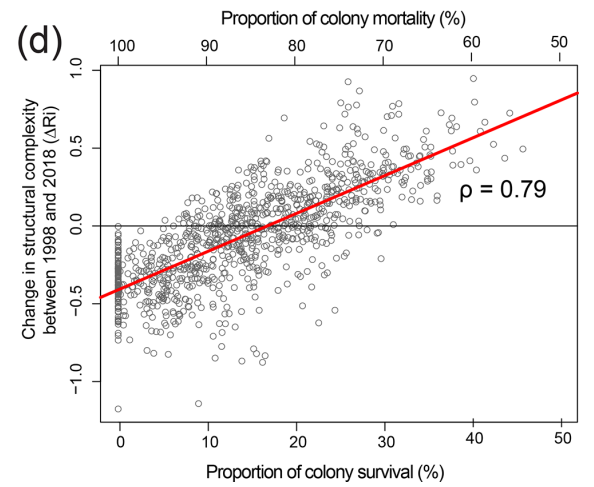

Figure 3. (a) Cross-sectional structural model of Orbicella annularis, indicating the method of estimating structural complexity ( $R$ refers to the surface perimeter/width) and changes in $R$ in 1998 (100\% live prior to mortality) and 2018 following mortality. (b) Results of 1000 model simulations of changes in structural complexity between 1997 and 2018 (grey lines) and average values across simulations (red line). (c) Change in the structural complexity between 1998 and $2018(\Delta R)$ of 1000 simulated colonies against colony size, and (d) the proportion of colony survival/mortality.

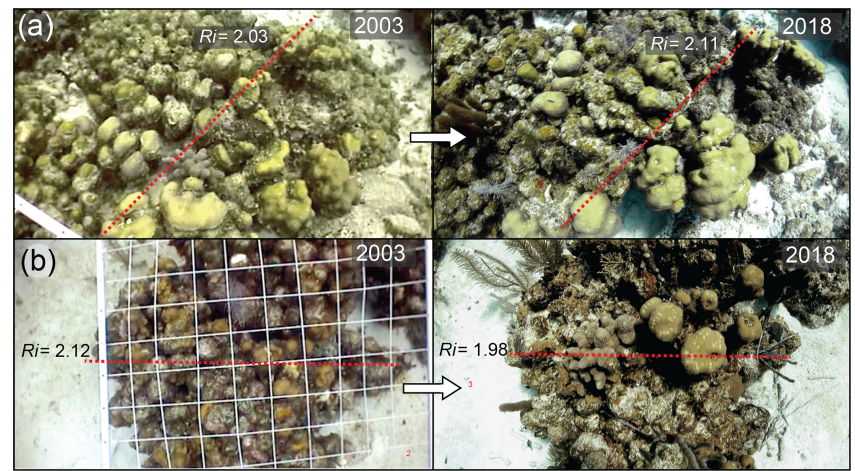

Figure 4. (a-b) Paired photographs of Orbicella. annularis colonies from 2003 (5 years post-disturbance) and 2018 (20 years post-disturbance) and the structural complexity $(R)$ derived from model simulations, showing the growth (vertical extension) of surviving ramets above the colony and the erosion of dead ramets in 2018.

Glovers Reef, but it may also reflect regional differences in the structure of bioeroding herbivore assemblages. These two studies likely reflect the extremes of the bioerosionary spectrum on Caribbean reefs, and future research should focus on understanding factors that render some frameworks more re- silient than others. While secondary cementation played an important role in hardening Holocene reef frameworks (Gischler and Hudson, 2004), the geochemical evidence (consistent initial uranium concentrations) within modern $O$. annularis skeletons from Long Caye (Roff et al., 2015) suggests that secondary cementation may not necessarily play an important reinforcing role in modern corals over at least decadal time frames.

\subsection{Changing functional roles of structural complexity}

At reef scales, $O$. annularis forms structurally complex frameworks that underpin species richness on Caribbean coral reefs (Newman et al., 2015). Prior to the 1998 disturbance events, the narrow crevices between $O$. annularis ramets provided critical refuge for scleractinian coral recruits (Mumby, 1999), juvenile and small-bodied Caribbean reef fish (Nemeth, 1998; Alvarez-Filip et al., 2011), and the eroding echinoids Echinometra viridis (Sammarco, 1982, Fig. 5a) and juvenile Diadema antillarum (Lessios, 1998). E.viridis are highly abundant in patch reefs and lagoonal reefs throughout Belize (Brown-Saracino et al., 2007), yet they are historically less common on deeper, exposed forereef habitats such as Long Caye (Peter J. Mumby, personal observation, 1998). D. antillarum have been histori- 
(a)

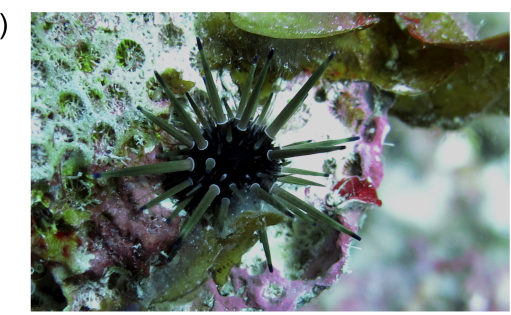

(b)

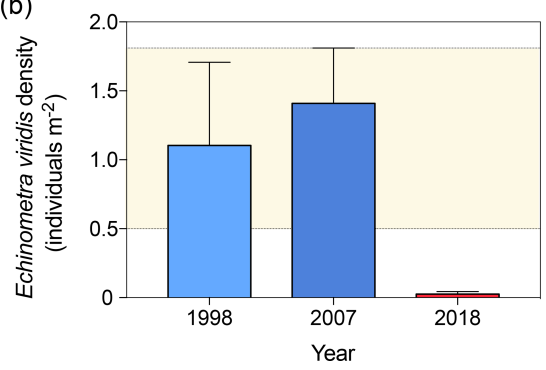

Figure 5. (a) Individual of Echinometra viridis among Orbicella annularis ramets at Long Caye in 2018 maintaining a cropped algae-free territory. (b) The density of E. viridis in the 1998, 2007, and 2018 surveys (the error band represents the maximum upper and lower standard deviation of the 1998 and 2008 surveys).

cally rare on the windward reef slope at Glovers Reef (Peter J. Mumby, personal observation, 1998) following the Caribbean-wide die-off in the early 1980s (Lessios, 1988), although surveys prior to the mass bleaching event in 1998 indicate that $O$. annularis frameworks supported a population of the smaller urchin E. viridis at densities of $1.1 \pm$ 0.6 individuals $\mathrm{m}^{-2}$ (Fig. 5b). As E. viridis are largely limited to crevice microhabitats due to high rates of predation (McClanahan, 1999), we hypothesize that the observed longterm changes in microhabitat complexity among crevices at Long Caye allowed predatory fish, such as triggerfish (Balistidae) and porgies (Sparidae), increased access to these areas. In $2007, E$. viridis was observed among $O$. annularis microhabitats at a comparable density to 1998 surveys, averaging $1.5 \pm 0.4$ individuals $\mathrm{m}^{-2}$ to a maximum of 14.3 individuals $\mathrm{m}^{-2}$ (Fig. 4b). A total of 10 years later, in 2018, we repeated surveys across the same study area at Long Caye, and only a single E. viridis was recorded in 40 colonies, resulting in an average density of just $0.02 \pm 0.02$ individuals $\mathrm{m}^{-2}$ (Fig. 5b).

While further experimental work is needed to quantify size thresholds of refugia by which urchins escape predation, these observations are consistent with the hypothesis that bioerosion of reef frameworks results in a reduced crevice depth for refuge, which, in turn, affects $E$. viridis densities by allowing invertivorous fish increased access to these areas, resulting in higher urchin mortality. Declines in the minimum ramet depth from $6.6 \pm 3.9 \mathrm{~cm}$ in 2007 to $4.8 \pm 2.1 \mathrm{~cm}$ in 2018 (Fig. 2c) are consistent with our previous U-Th estimates of bioerosion at Long Caye (Roff et al., 2015). We hypothesize that as $O$. annularis ramets erode, the loss of the upper ramet lobes results in increased ramet spacing and a wider aperture of the crevices. As parrotfish preferentially target convex surfaces of dead coral substrates (Roff et al., 2011), bioerosion of ramet edges can further widen the aperture of crevices, further facilitating invertivore access and diminishing refuge potential. Population dynamics of urchins are complex and result from complex interactions between topdown and bottom-up factors (Tebbett and Bellwood, 2018). Higher biomass of invertivores inside of marine protected areas can substantially increase predation pressure on urchins (Harborne et al., 2009) and may explain the rapid decline in E. viridis at Long Caye following diminished refuge potential between surveys. As Long Caye has been an enforced marine reserve since 1996, an alternative explanation for our observed data could be that urchin numbers have declined in response to increased predation pressure following the recovery of invertivorous fish assemblages. While plausible, we discount this hypothesis as invertivores were not heavily exploited prior to 1996 when the reserve was established, and surveys of fish assemblages indicate no change in invertivores over time (Peter J. Mumby, personal observation, 2018).

Densities of E. viridis in the deeper exposed fore-reef habitat at Long Caye are substantially lower than reported for other shallow patch reef and lagoonal reef habitats in Belize (as high as $40 \pm 7$ individuals $\mathrm{m}^{-2}$, Brown-Saracino et al., 2007). However, even at low densities $\left(<2\right.$ individuals $\left.\mathrm{m}^{-2}\right)$ the E. viridis density is positively related to coral cover (Bologna et al., 2012), implying a functional link. As $E$. viridis can play an important role in structuring reef communities by maintaining algae-free space within ramet crevices (Fig. 5a) and, in turn, facilitating coral recruitment (Sammarco, 1982), losses of these urchins may have resulted in small-scale increases in macroalgal cover within the $O$. annularis framework microhabitats - notably Lobophora spp. (Fig. 1c) - which can reduce coral recruitment and impede future recovery potential (Mumby et al., 2007). As an ecosystem engineer, the structural complexity constructed by $O$. annularis provides critical refuge for a diverse range of invertebrate fauna (Buss and Jackson, 1979; Idjadi and Edmunds, 2006). As diversity is positively related to structural complexity and not coral cover (Idjadi and Edmunds, 2006), we expect to see similar declines in other motile and sessile invertebrate taxa that seek refuge in $O$. annularis microhabitats.

\section{Structural complexity and the decline in reef frameworks in the 21 st century}

In recent decades, declines in coral cover and losses of keystone species have resulted in region-wide reductions in structural complexity throughout the Caribbean (AlvarezFilip et al., 2009). Here we highlight how small-scale changes in microhabitat complexity have the potential to alter ecological interactions that can impact recovery dynamics 
in ways that are undetectable using standardized metrics of structural complexity.

While losses of key microhabitat complexity may have cascading effects on diversity and ecosystem function, our results indicate that structural complexity at colony scales can be remarkably robust. Given the recent widespread recruitment failure of Caribbean corals (Hughes and Tanner, 2000) and the low recruitment rates of $O$. annularis in general (Edmunds, 2002), the potential for recovery and the long-term future of $O$. annularis frameworks at Long Caye in the 21 st century is unclear. However, 2 decades after mass mortality at Long Caye, levels of coral cover in 2018 remain above the $\sim 10 \%$ live-coral-cover threshold needed to maintain a positive state of reef accretion (Roff et al., 2015; Perry et al., 2013). While not explicitly incorporated in our erosion model, slower rates of external bioerosion on the sides of ramets and ongoing bioerosion from microand macro-borers over decadal scales (Roff et al., 2015) will likely weaken skeletal structural integrity in $O$. annularis (Highsmith et al., 1983), facilitating mechanical breakage and storm-driven loss of now protruding surviving ramets (Fig. S1) and likely resulting in non-linear increases in framework loss over longer timescales (2050 and beyond).

\section{Methods}

This study was conducted in Long Caye (Glovers Reef, Belize, Fig. 1a). The reef framework at Long Caye is formed primarily from monospecific stands of $O$. annularis (Ellis and Solander, 1786) that experienced widespread mortality following anomalously high water temperatures (29$32^{\circ} \mathrm{C}$ ) between early September and mid-November 1998 and during hurricane Mitch, which occurred simultaneously (Mumby, 1999). Field data were collected in 1998, 2003, 2007, and 2018 from an approximately $400 \mathrm{~m}^{2}$ area of monospecific $O$. annularis-dominated framework of at a depth of between 6 and $12 \mathrm{~m}$. O. annularis forms part of a species complex (the "Orbicella annularis species complex") along with $O$. faveolata and $O$. franksi. Each species within the complex exhibits a preferred depth zone: $O$. faveolata dominates shallow reef habitats, $O$. annularis dominates mid-depth habitats, and $O$. franksi is found in deeper water (Pandolfi and Budd, 2008).

\subsection{Microhabitat complexity}

Surveys and measurements of $O$. annularis colonies were conducted at a depth of between 6 and $12 \mathrm{~m}$ at Long Caye in March 2007 and May 2018. At both time points, colonies of $O$. annularis were selected among the framework at random using a system of fin-kicks and compass bearings. A minimum distance of $\sim 5 \mathrm{~m}$ was maintained between measured colonies, and ramets with signs of recent death were avoided. For each colony, we selected neighbouring ramet pairs from the central part of the colony ( $n=2-3$ per colony) and assigned them to one of three states: "live-live" pairing, "livedead" pairing, or "dead-dead" pairing ( $n=20$ ramet pair measurements for each state in 2007; $n=30$ ramet pair measurements for each state in 2018). The difference in height between each neighbouring ramet pair was quantified using a ruler or calipers to determine differences in the microhabitat complexity within $O$. annularis colonies. Differences between 2007 and 2018 were tested with a linear mixed effects model using R software (R Core Team, 2019) with "year" and "state" as fixed factors and "colony" as a random factor.

\subsection{Structural complexity}

To assess changes in rugosity at the colony scale in the 2 decades following the mass mortality, we created a structural model of $O$. annularis colonies that was parameterized using field data collected at Long Caye. The surface structural complexity of $O$. annularis colonies was modelled using a simple cross-sectional topography of ramets and colony widths (Fig. 4a, see R code in the Supplement). Colony widths were determined from in situ measurements of 95 colonies at Long Caye in 2000, and ramet heights (from the top to the base of the ramet within colonies) and widths were measured from 30 ramets within colonies in 2000 (Roff et al., 2015). The model simulates 1000 colonies of $O$. annularis, randomly sampling from colony width measurements, and uses measurements of ramet diameter and ramet spacing to determine the number of ramets within colonies. Prior to the 1998 mortality event, the ratio of live to dead ramets within colonies was determined from surveys of predisturbance $O$. annularis in 1998, where $97.8 \%$ of $O$. annularis ramets were alive (Roff et al., 2015). The ratio of live to dead ramets 20 years after the 1998 mortality event was determined from surveys of 25 colonies of $O$. annularis at Long Caye in 2018. Surviving ramets were subject to annual linear extension (sampled at random from CT-scan-derived skeletal growth measurements at Long Caye between 2006 and 2011; Roff et al., 2015), whereas dead ramets underwent annual external linear bioerosion (sampled at random from U-Th-derived measurements of $O$. annularis at Long Caye between 1998 and 2011; Roff et al., 2015). Annual changes in structural complexity within each simulated colony between 1998 and 2018 was measured using the rugosity index ( $R$; Alvarez-Filip et al., 2009), which is a ratio between the width of the colony and the external surface (i.e. the sum of ramet height, ramet width, and inter-ramet spacing). Correlations between changes in rugosity (1998-2018) and colony width, post-bleaching survival, and both the number of live and dead ramets within simulated colonies was determined using Pearson's product moment correlation coefficient $(\rho)$ with the cor.test function ("stats" package) in R (R Core Team, 2019). 


\subsection{Urchin densities}

To examine local ecological impacts of changes in the ramet size distribution, we conducted a census of the density of the urchin Echinometra viridis, which occupies the interstitial space between ramets. Surveys of at Long Caye in 1998 were conducted using five $10 \mathrm{~m} \times 0.5 \mathrm{~m}$ transects and found that urchins were dominated by E.viridis within ramets of $O$. annularis framework (Mumby et al., 2005). In subsequent survey years (2007 and 2018), urchin surveys were conducted on a per colony basis, and the number of urchins within each $O$. annularis colony was standardized to the colony area to give the number of individuals per square metre (2007: $n=50$ colonies; 2018: $n=40$ colonies).

Data availability. The complete $\mathrm{R}$ code for the structural model is provided in the Supplement, and underlying survey data are available upon request.

Supplement. The supplement related to this article is available online at: https://doi.org/10.5194/bg-17-5909-2020-supplement.

Author contributions. PJM, GR, and JJ collected the survey data. GR was responsible for the structural complexity model and wrote the original draft of the paper. GR and PJM reviewed and edited the final article.

Competing interests. The authors declare that they have no conflict of interest.

Acknowledgements. We are grateful to the Belize Department of Fisheries for permission to undertake this study and for support from the Smithsonian research station at Carrie Bow Cay Field Station.

Financial support. This research has been supported by the ARC Centre of Excellence for Coral Reef Science.

Review statement. This paper was edited by S. Wajih A. Naqvi and reviewed by Brett Taylor and one anonymous referee.

\section{References}

Almany, G. R.: Does increased habitat complexity reduce predation and competition in coral reef fish assemblages?, Oikos, 106, 275-284, 2004.

Alvarez-Filip, L., Dulvy, N. K., Gill, J. A., Cote, I. M., and Watkinson, A. R.: Flattening of Caribbean coral reefs: region-wide de- clines in architectural complexity, P. Roy. Soc. B-Biol. Sci., 276, 3019-3025, 2009.

Alvarez-Filip, L., Gill, J. A., and Dulvy, N. K.: Complex reef architecture supports more small-bodied fishes and longer food chains on Caribbean reefs, Ecosphere, 2, 1-17, https://doi.org/10.1890/Es11-00185.1, 2011.

Aronson, R. B., Precht, W. F., Toscano, M. A., and Koltes, K. H.: The 1998 bleaching event and its aftermath on a coral reef in Belize, Mar. Biol., 141, 435-447, https://doi.org/10.1007/s00227002-0842-5, 2002.

Beukers, J. S. and Jones, G. P.: Habitat complexity modifies the impact of piscivores on a coral reef fish population, Oecologia, 114, 50-59, 1998.

Bologna, P. A. X., Webb-Wilson, L., Connelly, P., and Saunders, J. E.: A new baseline for Diadema antillarum, Echinometra viridis, E. lucunter, and Eucidaris tribuloides populations within the Cayos Cochinos MPA, Honduras, Gulf and Caribbean Research, 24, 1-5, 2012.

Brown-Saracino, J., Peckol, P., Curran, H. A., and Robbart, M. L.: Spatial variation in sea urchins, fish predators, and bioerosion rates on coral reefs of Belize, Coral Reefs, 26, 71-78, https://doi.org/10.1007/s00338-006-0159-9, 2007.

Bruckner, A. W. and Bruckner, R. J.: Consequences of yellow band disease (YBD) on Montastraea annularis (species complex) populations on remote reefs off Mona Island, Puerto Rico, Dis. Aquat. Organ., 69, 67-73, 2006.

Bruno, J. F., Petes, L. E., Harvell, C. D., and Hettinger, A.: Nutrient enrichment can increase the severity of coral diseases, Ecol. Lett., 6, 1056-1061, https://doi.org/10.1046/j.14610248.2003.00544.x, 2003.

Budd, A. F. and Klaus, J. S.: The origin and early evolution of the Montastraea "annularis" species complex (Anthozoa: Scleractinia), J. Paleontol., 75, 527-545, 2001.

Buss, L. W. and Jackson, J. B. C.: Competitive networks: nontransitive competitive relationships in cryptic coral reef environments, Am. Nat., 113, 223-234, 1979.

Clements, K. D., German, D. P., Piche, J., Tribollet, A., and Choat, J. H.: Integrating ecological roles and trophic diversification on coral reefs: multiple lines of evidence identify parrotfishes as microphages, Biol. J. Linn. Soc., 120, 729-751, 2017.

Edmunds, P. J.: Long-term dynamics of coral reefs in St. John, US Virgin Islands, Coral Reefs, 21, 357-367, https://doi.org/10.1007/s00338-002-0258-1, 2002.

Edmunds, P. J. and Elahi, R.: The demographics of a 15-yr decline in cover of the Caribbean reef coral Montastraea annularis, Ecol. Monogr., 77, 3-18, 2007.

Edmunds, P. J.: A quarter-century demographic analysis of the Caribbean coral, Orbicella annularis, and projections of population size over the next century, Limnol. Oceanogr., 60, 840-855, https://doi.org/10.1002/lno.10075, 2015.

Ellis, J. and Solander, D.: The Natural History of many curious and uncommon Zoophytes, collected from various parts of the Globe. Systematically arranged and described by the late Daniel Solander, Benjamin White \& Son, London, 1786.

Ferrari, R., Gonzalez, M., and Mumby, P. J.: Size matters in the competition between corals and macroalgae, Mar. Ecol.-Prog. Ser., 467, 77-88, 2012.

Foster, N. L., Paris, C. B., Kool, J. T., Baums, I. B., Stevens, J. R., Sanchez, J. A., Bastidas, C., Agudelo, C., Bush, P., Day, 
O., Ferrari, R., Gonzalez, P., Gore, S., Guppy, R., McCartney, M. A., McCoy, C., Mendes, J., Srinivasan, A., Steiner, S., Vermeij, M. J. A., Weil, E., and Mumby, P. J.: Connectivity of Caribbean coral populations: complementary insights from empirical and modelled gene flow, Mol. Ecol., 21, 1143-1157, https://doi.org/10.1111/j.1365-294X.2012.05455.x, 2012.

Foster, N. L., Baums, I. B., Sanchez, J. A., Paris, C. B., Chollett, I., Agudelo, C. L., Vermeij, M. J. A., and Mumby, P. J.: Hurricane-Driven Patterns of Clonality in an Ecosystem Engineer: The Caribbean Coral Montastraea annularis, Plos One, 8, e53283, https://doi.org/10.1371/journal.pone.0053283, 2013.

Geister, J.: The influence of wave exposure on the ecological zonation of Caribbean coral reefs, Proceedings of the Third International Coral Reef Symposium, Rosenstiel School of Marine and Atmospheric Science, Miami, Florida, 23-29, 1977.

Gischler, E.: Accretion patterns in Holocene tropical coral reefs: do massive coral reefs in deeper water with slowly growing corals accrete faster than shallower branched coral reefs with rapidly growing corals?, Int. J. Earth Sci., 97, 851-859, https://doi.org/10.1007/s00531-007-0201-3, 2008.

Gischler, E. and Hudson, J. H.: Holocene development of the Belize Barrier Reef, Sediment. Geol., 164, 223-236, https://doi.org/10.1016/j.sedgeo.2003.10.006, 2004.

Glynn, P. W.: El Niño warming, coral mortality and reef framework destruction by echinoid bioerosion in the Eastern Pacific, Galaxea, 7, 129-160, 1988.

Glynn, P. W. and Manzello, D.: Bioerosion and coral reef growth: a dynamic balance, in: Coral Reefs in the Anthropocene, edited by: Birkeland, C., Springer, 67-97, 2015.

Halley, R. B., Swart, P. K., Dodge, R. E., and Hudson, J. H.: Decadescale trend in sea water salinity revealed through $\delta^{18} \mathrm{O}$ analysis of Montastraea Annularis annual growth bands, B. Mar. Sci., 54, 670-678, 1994.

Harborne, A. R., Renaud, P. G., Tyler, E. H. M., and Mumby, P. J.: Reduced density of the herbivorous urchin Diadema antillarum inside a Caribbean marine reserve linked to increased predation pressure by fishes, Coral Reefs, 28, 783-791, https://doi.org/10.1007/S00338-009-0516-6, 2009.

Hein, F. J. and Risk, M. J.: Bio-erosion of coral heads - inner patch reefs, Florida Reef Tract, B. Mar. Sci., 25, 133-138, 1975.

Highsmith, R. C., Lueptow, R. L., and Schonberg, S. C.: Growth and bioerosion of three massive corals on the Belize barrier reef, Mar. Ecol.-Prog. Ser., 13, 261-271, 1983.

Hughes, T. P. and Tanner, J. E.: Recruitment failure, life histories, and long-term decline of Caribbean corals, Ecology, 81, 2250 2263, 2000.

Hutchings, P. A.: Biological Destruction of Coral Reefs - a Review, Coral Reefs, 4, 239-252, https://doi.org/10.1007/Bf00298083, 1986.

Idjadi, J. A. and Edmunds, P. J.: Scleractinian corals as facilitators for other invertebrates on a Caribbean reef, Mar. Ecol.-Prog. Ser., 319, 117-127, 2006.

Kennedy, E. V., Perry, C. T., Halloran, P. R., Iglesias-Prieto, R., Schonberg, C. H. L., Wisshak, M., Form, A. U., CarricartGanivet, J. P., Fine, M., Eakin, C. M., and Mumby, P. J.: Avoiding coral reef functional collapse requires local and global action, Curr. Biol., 23, 912-918, 2013.
Knowlton, N. and Jackson, J. B. C.: Shifting baselines, local impacts, and global change on coral reefs, Plos Biol., 6, 215-220, https://doi.org/10.1371/journal.pbio.0060054, 2008.

Kuffner, I. B., Toth, L. T., Hudson, J. H., Goodwin, W. B., Sathakopoulos, A., Bartlett, L. A., and Whitcher, E. M.: Improving estimates of coral reef construction and erosion with in situ measurements, Limnol. Oceanogr., 64, 2283-2294, https://doi.org/10.1002/lno.11184, 2019.

Lessios, H. A.: Mass mortality of Diadema antillarum in the Caribbean: what have we learned?, Annu. Rev. Ecol. Syst., 19, 371-393, 1988.

Lessios, H. A.: Shallow water echinoids of Cayos Cochinos, Honduras, Rev. Biol. Trop., 46, 95-101, 1998.

McClanahan, T. R.: Predation and the control of the sea urchin Echinometra viridis and fleshy algae in the patch reefs of Glovers Reef, Belize, Ecosystems, 2, 511-523, 1999.

Moberg, F. and Folke, C.: Ecological goods and services of coral reef ecosystems, Ecol. Econ., 29, 215-233, 1999.

Mumby, P. J.: Bleaching and hurricane disturbances to populations of coral recruits in Belize, Mar. Ecol.-Prog. Ser., 190, 27-35, 1999.

Mumby, P. J., Foster, N. L., and Fahy, E. A. G.: Patch dynamics of coral reef macroalgae under chronic and acute disturbance, Coral Reefs, 24, 681-692, https://doi.org/10.1007/s00338-005-0058-5, 2005.

Mumby, P. J., Harborne, A. R., Williams, J., Kappel, C. V., Brumbaugh, D. R., Micheli, F., Holmes, K. E., Dahlgren, C. P., Paris, C. B., and Blackwell, P. G.: Trophic cascade facilitates coral recruitment in a marine reserve, P. Natl. Acad. Sci. USA, 104, 8362-8367, https://doi.org/10.1073/pnas.0702602104, 2007.

Nemeth, R. S.: The effect of natural variation in substrate architecture on the survival of juvenile bicolor damselfish, Environ. Biol. Fish., 53, 129-141, 1998.

Newman, S. P., Meesters, E. H., Dryden, C. S., Williams, S. M., Sanchez, C., Mumby, P. J., and Polunin, N. V. C.: Reef flattening effects on total richness and species responses in the Caribbean, J. Anim. Ecol., 84, 1678-1689, https://doi.org/10.1111/13652656.12429, 2015.

Nugues, M. M.: Impact of a coral disease outbreak on coral communities in St. Lucia: What and how much has been lost?, Mar. Ecol.-Prog. Ser., 229, 61-71, 2002.

Pandolfi, J. M. and Budd, A. F.: Morphology and ecological zonation of Caribbean reef corals: the Montastraea "annularis" species complex, Mar. Ecol.-Prog. Ser., 369, 89-102, 2008.

Pandolfi, J. M. and Jackson, J. B. C.: Ecological persistence interrupted in Caribbean coral reefs, Ecol. Lett., 9, 818-826, https://doi.org/10.1111/J.1461-0248.2006.00933.X, 2006.

Pantos, O., Cooney, R. P., Le Tissier, M. D. A., Barer, M. R., and Bythell, J.: The bacterial ecology of a plague-like disease affecting the Caribbean coral Montastrea annularis, Environ. Microbiol., 5, 370-382, 2003.

Perry, C., Murphy, G. N., Kench, P. S., Smithers, S. G., Edinger, E. N., Steneck, R. S., and Mumby, P. J.: Caribbean-wide decline in carbonate production threatens coral reef growth, Nat. Commun., 4, 1402, https://doi.org/10.1038/ncomms2409, 2013.

Perry, C. T., Murphy, G. N., Kench, P. S., Edinger, E. N., Smithers, S. G., Steneck, R. S., and Mumby, P. J.: Changing dynamics of Caribbean reef carbonate budgets: emergence of reef bioeroders as critical controls on present and future reef 
growth potential, P. Roy. Soc. B-Biol. Sci., 281, 20142018, https://doi.org/10.1098/rspb.2014.2018, 2014.

R Core Team: R: A language and environment for statistical computing, R Foundation for Statistical Computing, Vienna, Austria, 2019.

Roff, G., Ledlie, M. H., Ortiz, J. C., and Mumby, P. J.: Spatial Patterns of Parrotfish Corallivory in the Caribbean: The Importance of Coral Taxa, Density and Size, PLoS ONE, 6, e29133, https://doi.org/10.1371/journal.pone.0029133, 2011.

Roff, G., Zhao, J. X., and Mumby, P. J.: Decadal-scale rates of reef erosion following $\mathrm{El}$ Nino-related mass coral mortality, Glob. Change Biol., 21, 4415-4424, https://doi.org/10.1111/gcb.13006, 2015.

Rogers, A., Blanchard, J. L., and Mumby, P. J.: Fisheries productivity under progressive coral reef degradation, J. Appl. Ecol., 55, 1041-1049, https://doi.org/10.1111/1365-2664.13051, 2018.

Sammarco, P. W.: Echinoid grazing as a structuring force in coral communities - whole reef manipulations, J. Exp. Mar. Biol. Ecol., 61, 31-55, 1982.
Sheppard, C. R. C., Spalding, M., Bradshaw, C., and Wilson, S.: Erosion vs. recovery of coral reefs after $1998 \mathrm{El}$ nino: Chagos reefs, Indian Ocean, Ambio, 31, 40-48, 2002.

Szmant, A. M. and Gassman, N. J.: The effects of prolonged bleaching on the tissue biomass and reproduction of the reef coral Montastraea annularis, Coral Reefs, 8, 217-224, 1990.

Tebbett, S. B. and Bellwood, D. R.: Functional links on coral reefs: Urchins and triggerfishes, a cautionary tale, Mar. Environ. Res., 141, 255-263, https://doi.org/10.1016/j.marenvres.2018.09.011, 2018.

van Hooidonk, R., Maynard, J. A., Liu, Y. Y., and Lee, S. K.: Downscaled projections of Caribbean coral bleaching that can inform conservation planning, Glob. Change Biol., 21, 3389-3401, https://doi.org/10.1111/gcb.12901, 2015. 